\title{
Evaluation of International Standards of Management of Communication and Information Technology (MCIT) in Khorasan Razavi Hospitals from the Perspective of Managers
}

\author{
Saeed Shojaei1 ${ }^{1}$, Fereshteh Farzianpour ${ }^{2 *}$, Mohammad Arab ${ }^{2}$, Abbas Rahimi Foroushani ${ }^{3}$, \\ Esmaeil Hosseinzadeh Roknabadi ${ }^{2}$ \\ ${ }^{1}$ Department of Health Management and Economic, School of Public Health, International Campus, Tehran \\ University of Medical Sciences, Tehran, Iran \\ ${ }^{2}$ Department of Health Management and Economics, School of Public Health, Tehran University of Medical \\ Sciences, Tehran, Iran \\ ${ }^{3}$ Department of Epidemiology and Biostatistics, Tehran University of Medical Sciences, Tehran, Iran \\ Email: s.shojaei2011@gmail.com, ${ }^{*}$ farzianp@sina.tums.ac.ir, arabmoha@tums.ac.ir, rahimifo@tums.ac.ir
}

Received 1 July 2015; accepted 2 August 2015; published 5 August 2015

Copyright (C) 2015 by authors and Scientific Research Publishing Inc.

This work is licensed under the Creative Commons Attribution International License (CC BY). http://creativecommons.org/licenses/by/4.0/

(c) (i) Open Access

\section{Abstract}

The general goal of the management of communication and information technology (MCIT) in the health sector, is to accelerate collecting, achieving and supporting the health system processes, and effective decision-making for managing this system; because preparing and providing health care services for society is very complex, and highly dependent on the information system. The aim of this investigation is to determine the mean scores of the possibility of implementing the MCIT standards in Khorasan Razavi hospitals, from the perspective of managers. This was a cross sectional descriptive-analytic study conducted in two steps in all hospitals. In the first step, the applicability of the standards in hospitals was studied. In the second step, the current status of hospitals was compared with international standards MCIT. In order to determine the validity of the questionnaires, opinions of professors and experts were acquired. Regarding the reliability, the SPSS V. 12 calculated the value of Cronbach's to be 0.95 for the first questionnaire and 0.86 for the second questionnaire. Data were analyzed using statistic tests of one way ANOVA and t-test. The level of significance was fixed at 0.5 . In the 16 hospitals studied, the mean and standard deviation of MCIT were $(57.25 \pm 13.74)$. The MCIT standards are applicable in hospitals of Khorasan

\footnotetext{
"Corresponding author.
}

How to cite this paper: Shojaei, S., Farzianpour, F., Arab, M., Foroushani, A.R. and Roknabadi, E.H. (2015) Evaluation of International Standards of Management of Communication and Information Technology (MCIT) in Khorasan Razavi Hospitals from the Perspective of Managers. Health, 7, 920-926. http://dx.doi.org/10.4236/health.2015.78109 
Razavi according to half (49.4\%) of managers; nonetheless, their application requires greater efforts by the hospitals.

\title{
Keywords
}

\author{
Evaluation, International Standards, Management of Communication and Information Technology, \\ Managers, Hospitals
}

\section{Introduction}

MCIT refers to a group of processes, which are implemented to help increase the efficiency and effectiveness of a health care organization (hospital), in order to be able to do its duty well, and achieve the desired goals [1]. To ensure the effective implementation and positive effect on health care services, MCIT assessment is very important. This assessment includes measuring and monitoring all aspects of planning, progress, implementation, and related activities, and results which have led to decision-making in that specific environment [2]. Systematic assessment of clinical activity of health care personnel (MCIT) helps to continuously improve their performance, prevent medical errors, and reduce stressful reactions, and their relevant costs, through conformity of software to the needs of employees and users of the network [3]. HIS users should also have a correct understanding of how the performance is; otherwise, HIS will lead to the failure of the system. If users who direct the HIS system, do not have the required knowledge about the system, achieving the desired objectives, which is MCIT, will become difficult [4]. Accordingly, thinkers of health domain have found the solution, in using MCIT standards, and accreditation of hospitals behaviors, and in order to gain more share in the market of health care services, and reduce their final prices, excellent organizations need to improve the quality of MCIT system, and they feel well the competition for this issue [5]. In the health care system, hospitals have a special place, evaluation of the quality of MCIT system of the country's hospitals, provide a clear commitment to improve the quality and safety of patient care, ensure a safe care environment, and continually work to reduce risks that threaten patients and staff [6]. Accreditation, as an international model, is effective on qualitative evaluation and management tool. The use of MCIT international standards is a collection of various initiatives, planned based on standards in response to the growing demand, worldwide, for the evaluation of health care [7]. Quality and safety have its roots in the daily work of health care specialists, and other staff [8]. While physicians, nurses, and hospital officials seek to assess the patients' needs, and provide care, MCIT international standard, which is a domain of JCI international standards, can help them find out how they can create real reform and improvement, to help their patients and reduce risks [9]. The current study intends to analyze the status of MCIT I system in Khorasan Razavi hospitals, using the international standards of the management of communication and information (MCIT). Using the results obtained from the research, an image of the current status of these hospitals can be provided in this field, and an appropriate model can be designed to improve the quality of communication and information management system of the afore mentioned hospitals. This model can help the managers and officials of the Ministry of Health and Medical Education with future planning.

\section{Meatrials and Methods}

This is a cross-sectional descriptive-analytic study conducted in two steps in hospitals of Khorasan Razavi from July to December 2014. This study was approved by the Ethical Committee of Tehran University of Medical Sciences (TUMS) in 2013/6/10. About the nature and purpose of the study was explained to the participants. The subjects signed the informed consent form to participle in the study. In the first step, the applicability of the standards in the study environment was assessed with a questionnaire comprised of the MCI standards and 28 questions with three choices (applicable, relatively applicable, and inapplicable). The questionnaire contained 6 questions in the domain of standards for the field of communication with society, 2 in the domain of standards for the field of communication with patient and their families, 21 in the domain of standards for the field of notification among the suppliers inside and outside the organization 6 in the domain of standards for the field of notification among the suppliers inside and outside the organization, and 3 in the domain of standards for the field of leadership and planning, 14 in the domain of standards for the field of total data and information. The ques- 
tionnaires were completed by overall Cranach's “was determined to be 0.95 for the first questionnaire”. Then, in order to determine the impact of each question, the coefficient was calculated with omission of one question at a time. The findings indicated that the coefficients varied from 0.85 to 0.86 and omission of each question did not alter the coefficient significantly. Thus, the applicability of all standards was established and the second questionnaire used all measurement elements. In the second step, the sample size was determined in such a fashion as to allow a maximum error of estimation of 1 with a confidence of 95\%. Given the fact that there are 16 hospitals supervised by the hospitals of Khorasan Razavi, the sample size was determined to be 64 so that 4 individuals in each hospital, i.e. senior managers (manager and nursing manager) and personnel of office of clinical governance, completed the questionnaires. In two hospitals, however, due to presence of only one person in the office of clinical governance, only three questionnaires were completed, yielding a total of 62 questionnaires completed. The second questionnaire consisted of measurable elements of MCIT standards in the form of 63 questions with Yes/No answers. The questionnaire consisted of 19 questions in the domain of standards for the field of communication with society, 5 in the domain of standards for the field of communication with patient and their families, 22 in the domain of data standards for the field of notification among the suppliers inside and outside the organization, and 7 in the domain of standards for the field of leadership and planning, 24 in the domain of data standards for the field of the patients' clinical records 14 in the domain of standards for the field of total data and information. In order to determine the content validity of the questionnaires, opinions and suggestions of professors and experts of management of healthcare services were used. Regarding the reliability of questionnaires, the SPSS software version 12 determined the value of Cronbach's to be 0.95 for the first questionnaire and 0.86 for the second questionnaire. Data analysis was accomplished using SPSS software version 12 and statistical tests of one way ANOVA and t-test. The level of significance was fixed at 0.5.

\section{Results}

The 16 hospitals studied consisted of 4 (25.8\%) general hospitals and 12 (74.2\%) were specialized hospitals. The number of beds in hospitals ranged from 69 to 537, with a mean value of 249.7 and standard deviation of 145.6. In the present study, 16 top managers (100\%) completed the questionnaires. The field of study was management for 8 (50\%), medicine and nursing for 8 (50\%) respondents. The findings of the study, separated for each domain are as follows: Table 1 showed 43.8\% MCIT standards are applicable in hospitals of Khorasan Razavi according to half (49.4\%) of managers (Table 1 ).

Domain of standards for the field of communication with society: Then mean and standard deviation of score for this domain were for special hospitals and general hospitals $10 \pm 1.80$ and $10.50 \pm 1.91$, respectively (Table 2).

Domain of standards for the field of communication with patient and their families: The mean and standard deviation of score in this domain were $3.16 \pm 0.71$ and $2.75 \pm 0.95$ in special hospitals and general hospitals, respectively. 55 (88.7\%) of respondents answered positive to the measurable element "Do managers implement therapeutic protocols for conduct of procedures of communication with patient and their families?” while 46 (74.2\%) answered positive to the measurable element "Are tools and principles of quality improvement used for designing new procedures or modifying current procedures?”

Domain of standards for the field of notification among the suppliers inside and outside the organization: In this domain, the mean and standard deviation of score were $26.75 \pm 10.86$ and $28.25 \pm 11.26$ in special hospitals and general hospitals, respectively (Table 2).

Domain of standards for the field of leadership and planning: In this domain, the mean and standard deviation of score were $9.58 \pm 2.31$ and $10.05 \pm 1.91$ in special hospitals and general hospitals, respectively (Table 2).

Domain of standards for the field of the patients' clinical records: In the improvement domain, the mean and standard deviation were $4.91 \pm 1.08$ and $5.25 \pm 0.95$ in special hospitals and general hospitals, respectively (Table 2).

Domain of standards for the field of total data and information: In general, the mean and standard deviation of MCI scores in the hospitals studied were $54.41 \pm 15.32$ and $57.25 \pm 13.74$, in special hospitals and general hospitals respectively. The mean scores of general hospitals were higher compared to specialized hospitals in domains of leadership and planning. However, the general hospitals scored higher in domains of designing clinical and managerial (Table 2).

Evaluation of Factors Affecting Scores of Domains and MCI: 
Table 1. Absolute and relative frequency of MCIT applicability of standards in hospitals of in Khorasan Razavi from the perspective of managers in 2014.

\begin{tabular}{|c|c|c|c|c|}
\hline \multirow{2}{*}{ Domain } & Applicable & Relatively applicable & Inapplicable & Total \\
\hline & $\mathrm{N}(\%)$ & $\mathrm{N}(\%)$ & $\mathrm{N}(\%)$ & N (\%) \\
\hline The standards for the field of communication with society. & $7(43.8)$ & $5(31.2)$ & $4(25)$ & $16(100)$ \\
\hline $\begin{array}{l}\text { The standards for the field of communication with } \\
\text { patient and their families. }\end{array}$ & $5(31.2)$ & $7(43.8)$ & $4(25)$ & $16(100)$ \\
\hline $\begin{array}{l}\text { The standards for the field of notification among the } \\
\text { suppliers inside and outside the organization. }\end{array}$ & $8(50)$ & $4(25)$ & $4(25)$ & $16(100)$ \\
\hline The standards for the field of leadership and planning. & $8(50)$ & $5(31.2)$ & $3(18.8)$ & $16(100)$ \\
\hline The standards for the field of the patients' clinical records. & $7(43.8)$ & $8(50)$ & $1(6.2)$ & $16(100)$ \\
\hline The standards for the field of total data and information. & $7(43.8)$ & $6(37.5)$ & $3(18.8)$ & $16(100)$ \\
\hline MCIT & $7(43.8)$ & $6(37.5)$ & $3(18.8)$ & $16(100)$ \\
\hline
\end{tabular}

Table 2. Mean and standard deviation and results of t-test related to scores of each domain of MCTI for type of hospital in hospitals of Khorasan Razavi in 2015.

\begin{tabular}{|c|c|c|c|c|}
\hline Domain & $\mathrm{N}$ & Type of hospital & $\mathrm{X} \pm \mathrm{SD}$ & P-value \\
\hline \multirow{2}{*}{$\begin{array}{l}\text { The standards for the field of communication } \\
\text { with society. }\end{array}$} & 16 & Specialized & $10 \pm 1.80$ & \multirow{2}{*}{0.64} \\
\hline & 16 & General & $10.50 \pm 1.91$ & \\
\hline \multirow{2}{*}{$\begin{array}{l}\text { The standards for the field of communication } \\
\text { with patient and their families. }\end{array}$} & 16 & Specialized & $3.16 \pm 0.71$ & \multirow{2}{*}{0.36} \\
\hline & 16 & General & $2.75 \pm 0.95$ & \\
\hline \multirow{2}{*}{ The standards for the field of leadership and planning. } & 16 & Specialized & $26.75 \pm 10.86$ & \multirow{2}{*}{0.81} \\
\hline & 16 & General & $28.25 \pm 11.26$ & \\
\hline \multirow{2}{*}{$\begin{array}{l}\text { The standards for the field of notification among the } \\
\text { suppliers inside and outside the organization. }\end{array}$} & 16 & Specialized & $9.58 \pm 2.31$ & \multirow{2}{*}{0.48} \\
\hline & 16 & General & $10.50 \pm 1.91$ & \\
\hline \multirow{2}{*}{ The standards for the field of the patients' clinical records. } & 16 & Specialized & $4.91 \pm 1.08$ & \multirow{2}{*}{0.59} \\
\hline & 16 & General & $5.25 \pm 0.95$ & \\
\hline \multirow{2}{*}{ The standards for the field of total data and information. } & 16 & Specialized & $54.41 \pm 15.32$ & \multirow{2}{*}{0.74} \\
\hline & 16 & General & $57.25 \pm 13.74$ & \\
\hline \multirow{2}{*}{ MCIT } & 16 & Specialized & $54.41 \pm 15.32$ & \multirow{2}{*}{0.74} \\
\hline & 16 & General & $57.25 \pm 13.7$ & \\
\hline
\end{tabular}

According to the t-test, the type of hospital do not affect any of the domains and MCTI (Table 2 and Table 3). Analysis of variance indicated that the position of respondents didn't influence the domains and MCIT (Table 4).

\section{Discussion}

Domain of standards for the field of communication with society: Farzianpour et al. states that the managers assume a particularly important role in any organization and knowledge of communication with society a major responsibility of managers alongside planning, organizing and controlling [10]. According to our findings, 43.8\% of respondents believed that the standards of this domain are being implemented excellently. Azizi et al. (2010; Moradi et al., 2009) reported the rates of observance of communication with society standards to be equal to $78 \%, 63 \%$ and $54 \%$ in three hospitals of Iran University of Medical Sciences [11]. 
Table 3. Mean and standard deviation and results of analysis of variance to scores of each domain of MCIT According to the number of beds in hospitals of Khorasan Razavi in 2014.

\begin{tabular}{|c|c|c|c|c|c|}
\hline \multirow{3}{*}{ Domain } & \multicolumn{5}{|c|}{ Indices \& test results domain } \\
\hline & $<109$ bed & $>110-245$ bed & $>246$ bed & Total & Test result \\
\hline & $\mathrm{X} \pm \mathrm{SD}$ & $\mathrm{X} \pm \mathrm{SD}$ & $\mathrm{X} \pm \mathrm{SD}$ & $\mathrm{X} \pm \mathrm{SD}$ & P-value \\
\hline $\begin{array}{l}\text { The standards for the field of } \\
\text { communication with society. }\end{array}$ & $10 \pm 2.16$ & $9.57 \pm 1.81$ & $11 \pm 1.41$ & $10.12 \pm 1.78$ & 0.41 \\
\hline $\begin{array}{l}\text { The standards for the field } \\
\text { of communication with } \\
\text { patient and their families. }\end{array}$ & $2.25 \pm 50$ & $3.28 \pm 0.75$ & $3.40 \pm 0.54$ & $3.06 \pm 0.77$ & 0.37 \\
\hline $\begin{array}{l}\text { The standards for the field } \\
\text { of leadership and planning. }\end{array}$ & $20.75 \pm 7.36$ & $26.85 \pm 11.21$ & $32.60 \pm 10.66$ & $27.12 \pm 10.60$ & 0.26 \\
\hline $\begin{array}{l}\text { The standards for the field of } \\
\text { notification among the suppliers } \\
\text { inside and outside the organization. }\end{array}$ & $9.25 \pm 2.75$ & $9 \pm 2.16$ & $11.40 \pm 0.98$ & $9.81 \pm 2.19$ & 0.14 \\
\hline $\begin{array}{l}\text { The standards for the field } \\
\text { of the patients' clinical records. }\end{array}$ & $4.5 \pm 1$ & $5 \pm 1.15$ & $5.4 .96 \pm 0.89$ & $5 \pm 1.03$ & 0.46 \\
\hline $\begin{array}{l}\text { The standards for the field } \\
\text { of total data and information. }\end{array}$ & $46.75 \pm 9.03$ & $53.71 \pm 16.04$ & $63.8 \pm 13.34$ & $55.12 \pm 14.54$ & 0.21 \\
\hline MCIT & $63.8 \pm 13.34$ & $55.12 \pm 14.54$ & $46.75 \pm 9.03$ & $53.71 \pm 16.04$ & 0.21 \\
\hline
\end{tabular}

Table 4. Mean and standard deviation and results of analysis of variance to scores of each domain of MCIT according to their field of studies in hospitals of Khorasan Razavi in 2014.

\begin{tabular}{|c|c|c|c|c|c|}
\hline \multirow{3}{*}{ Domain } & \multicolumn{5}{|c|}{ Indices \& test results domain } \\
\hline & Medical & Management & And other studies & Total & Test result \\
\hline & $\mathrm{X} \pm \mathrm{SD}$ & $\mathrm{X} \pm \mathrm{SD}$ & $\mathrm{X} \pm \mathrm{SD}$ & $\mathrm{X} \pm \mathrm{SD}$ & P-value \\
\hline $\begin{array}{l}\text { The standards for the field of } \\
\text { communication with society. }\end{array}$ & $10 \pm 2.06$ & $10.40 \pm 1.67$ & $10 \pm 1.41$ & $10.12 \pm 1.78$ & 0.92 \\
\hline $\begin{array}{l}\text { The standards for the field of } \\
\text { communication with patient } \\
\text { and their families. }\end{array}$ & $3.22 \pm 0.83$ & $2.80 \pm 0.83$ & $3 \pm 0$ & $3.06 \pm 0.77$ & 0.64 \\
\hline $\begin{array}{l}\text { The standards for the field } \\
\text { of leadership and planning. }\end{array}$ & $31.11 \pm 8.75$ & $22.85 \pm 12.98$ & $22.60 \pm 8.48$ & $27.12 \pm 10.60$ & 0.24 \\
\hline $\begin{array}{l}\text { The standards for the field of } \\
\text { notification among the suppliers inside } \\
\text { and outside the organization. }\end{array}$ & $10 \pm 2.06$ & $9 \pm 2.82$ & $11 \pm 0$ & $9.81 \pm 2.19$ & 0.54 \\
\hline $\begin{array}{l}\text { The standards for the field of the } \\
\text { patients' clinical records. }\end{array}$ & $5 \pm 1.11$ & $5.2 \pm 1.09$ & $4.5 \pm 0.70$ & $5 \pm 1.03$ & 0.74 \\
\hline $\begin{array}{l}\text { The standards for the field of total } \\
\text { data and information. }\end{array}$ & $59.33 \pm 13.91$ & $49.4 \pm 17.14$ & $50.5 \pm 9.19$ & $55.12 \pm 14.54$ & 0.45 \\
\hline MCIT & $59.33 \pm 13.91$ & $49.4 \pm 17.14$ & $50.5 \pm 9.19$ & $55.12 \pm 14.54$ & 0.45 \\
\hline
\end{tabular}

Domain of standards for the field of communication with patient and their families: Patients: health is affected by different healthcare procedures [12]. According to our findings, 31.2\% of questionnaires scored 5, indicating that $31.2 \%$ respondents believe that the standards of this domain are being implemented excellently. Sanaz Amirifar et al. (2010) reported the rate of observance of clinical procedures standards to be equal to $27 \%$ in the emergency ward of a general hospital of Tehran University of Medical Sciences. The discrepancy between our study and the one mentioned above may be accounted for by the fact that the latter was conducted only in one ward, i.e. the emergency department, whereas our study evaluated the procedure designing in all hospitals [13].

Domain of standards for the field of notification among the suppliers inside and outside the organization: Hospitals are required to present a report of their notification among the suppliers inside and outside the organi- 
zation and these results influence the health policies significantly [14]. Presenting a report requires standards for the field of notification among the suppliers inside and outside the organization. Our findings indicate that 50\% respondents believed that the standards of this domain are being implemented excellently. Sanaz Amirifar et al. (2010) reported the rate of observance of standards of standards for the field of notification among the suppliers inside and outside the organization and standards for the field of leadership and planning to be equal to $39.5 \%$ and $29.3 \%$, respectively, in the emergency ward of a general hospital of Tehran University of Medical Sciences [12].

Domain of standards for the field of leadership and planning: Farzianpour et al. (2015) reported the rates of observance of standards for the field of leadership and planning to be equal to $70 \%, 58.5 \%$ and $53 \%$ in three hospitals of Kurdestan University of Medical Sciences [10].

The findings of the present study and other studies indicate that implementation of MCIT and models of excellence and observing their requirements raise the score.

Domain of standards for the field of the patients' clinical records: Farzianpour et al. have highlighted the role or participation of workers and increasing their creativity in organizations for the purpose of perpetual quality improvement for patients' clinical records [15]. According to our findings, (43.8\%) respondents believed that the standards of this domain are being implemented excellently. Sanaz Amirifar et al. (2010) reported the rate of observance of standards of improvement to be equal to $31.6 \%$ in the emergency ward of a general and special hospitals of Tehran University of Medical Sciences [13]. The findings of other similar studies do not corroborate those of our study, presumably due to the fact that those studies have dealt with one hospital only.

Domain of standards for the field of total data and information: Our study indicated that (43.8\%) respondents believe that the standards of MCIT are being implemented excellently. In a study by Turani et al. (2010) on hospitals of Iran University of Medical Sciences, the mean rates of observance of standards of quality improvement and patient safety were $72 \%, 57.6 \%$ and $57.4 \%$. Among these, the hospital with an implemented EFQM excellence model had the highest score [16]. Ammenwerth et al. evaluated Effect of a nursing information system on the quality of information processing in nursing in hospitals and concluded that expansion of capacity of quality improvement requires investments and education [4]. Although the authors faced limitations for comparing the results with those of international studies, comparison with Iranian studies indicates that our hospitals are in an intermediate level regarding quality improvement and patient safety. Furthermore, hospitals that use excellence models and systems of quality management demonstrate a better status.

\section{Conclusion and Recommendation}

According to half (43.8\%) of managers, the MCIT standards are applicable in hospitals of Khorasan Razavi; however, their application requires greater efforts by the hospitals. Implementation and actualization of standards in hospitals require certain infrastructures such as better knowledge on the part of managers regarding the principles and tools of quality improvement, training personnel about the standards, implementation of models of quality management and organizational excellence, reinforcing the public affairs in hospitals and using hospital information system (MCIT, HIS, MISH) all of which influence the process of realization for standards of quality improvement and patient safety.

\section{Acknowledgements}

This study was part of the Ph.D. Dissertation of first author, conducted in Health care Management, department of Health Management and Economic, School of Public Health, International Campus, Tehran University of Medical Sciences, Tehran, Iran. The authors would like to thank all participants in this research, particularly key informants and managers who participated in the study.

\section{Declaration of Conflicting Interests}

The author(s) declared no potential conflicts of interest with respect to the research, authorship, and/or publication of this article.

\section{References}

[1] Farzianpour, F., Arab, M., Amoozagar, S., Fouroshani, A.R., Rashidian, A., Moghadam, M.N. and Hosseini, S. (2011) 
Evaluation of International Standards of Quality Improvement and Patient Safety (QPS) in Hospitals of Tehran University of Medical Sciences (TUMS) from the Managers’ Point of View. World Applied Sciences Journal, 15, 647-653.

[2] Ghazi-Saeedi, M., Davarpanah, A. and Safdari, R. (2007) Health Information Management. Mahan Publication, Tehran. [In Persian]

[3] Aggelidis, V.P. and Chatzoglou, P.D. (2012) Hospital Information Systems: Measuring End User Computing Satisfaction (EUCS). Journal of Biomedical Informatics, 45, 566-579. http://dx.doi.org/10.1016/j.jbi.2012.02.009

[4] Ammenwerth, E., Rauchegger, F., Ehlers, F., Hirsch, B. and Schaubmayr, Ch. (2011) Effect of a Nursing Information System on the Quality of Information Processing in Nursing: An Evaluation Study Using the HIS-Monitor Instrument. International Journal of Medical Informatics, 80, 25-38. http://dx.doi.org/10.1016/j.ijmedinf.2010.10.010

[5] Hosseini, A. (2006) Designing a Logical Model of Hospital Information System for Teaching General Hospitals of the Medical Universities in Tehran: 2005-2006. Ph.D. Thesis, Iran.

[6] Chen, R.F. and Hsiao, J.L. (2012) An Investigation on Physicians’ Acceptance of Hospital Information Systems: A Case Study. International Journal of Medical Informatics, 81, 810-820. http://dx.doi.org/10.1016/j.ijmedinf.2012.05.003

[7] Elbanna, A. (2010) From Intention to Use to Actual Rejection: The Journey of an e-Procurement System. Journal of Enterprise Information Management, 23, 81-99. http://dx.doi.org/10.1108/17410391011008914

[8] Aggelidis, V.P. and Chatzoglou, P.D. (2012) Hospital Information Systems: Measuring End User Computing Satisfaction (EUCS). Journal of Biomedical Informatics, 45, 566-579. http://dx.doi.org/10.1016/j.jbi.2012.02.009

[9] Meli, P.L. (2008) Perspectives of Health Information Management Faculty Use of an e-Learning Laboratory \& Technology Acceptance. Ph.D. Thesis, College of Education, University of Central Florida.

[10] Farzianpour, F., Foroushani, A.R., Rahmany, K. and Mehrabany, K.B. (2015) Evaluation of In-Service Training and Staff Qualifications and Education in Kurdistan University of Medical Sciences. Journal of Service Science and Management, 8, 332-338. http://dx.doi.org/10.4236/jssm.2015.83035

[11] Azizi, A., Hajavi, A., Haghani, H. and Shojaei Baghini, M. (2010) Respect Rate of Hospital Information System Criteria of American College of Physicians in Educational Hospitals of Iran, Tehran, and Shahid Beheshti Medical Sciences Universities. Health Information Management, 7, 323-329. [In Persian]

[12] Farzianpour, F., Nourijelyani, K., Zandiyan, H., Zahirian Moghadam, T. and Zahirian Moghadam, S. (2014) Accreditation Maternity and Obstetric Services (MOS), Based on the Accreditation Standards of the Joint Commission International (JCI). Health, 6, 2453-2460. http://dx.doi.org/10.4236/health.2014.618282

[13] Amirifar, S. and Farzianpour, F. (2010) Evaluation of Emergency Department in Emam Khomeyni Hospital Based on Standards Ministry of Health and Medical Education and Standards Joint Commission International. Thesis, Faculty of Paramedical, Tehran University of Medical Sciences. [In Persian]

[14] Farzianpour, F., Hosseini, S.H., Arani, S.S. and Bakhtiyari, A. (2014) Evaluation of International Standards of Patient and Family Rights (PFR) from Chief Nurses’ Point of View in Hospitals of Iran. Pensee Journal, 76, 372-382.

[15] Farzianpour, F., Hamedani, A.T., Godarzi, L., Askari, R. and Hosseini, S.S. (2013) Evaluation of Customer Relationship Management in a Teaching Hospital. American Journal of Applied Sciences, 10, 344-352.

http://www.thescipub.com/ajas.toc http://dx.doi.org/10.3844/ajassp.2013.344.352

[16] Turani, S., Zarnagh, R.K. and Farhadi, F. (2010) Readiness of Educational Hospitals of Iran. Readiness of Educational Hospitals of Iran University of Medical Sciences for Establishment Joint Commission International Accreditation Standards for Hospitals: Approach of Patient Centered, (May/10/2010), Olympic Hotel. Institute of Human Resource Empowerment, Iran. (In Persian) 